\title{
DIE SLAG VAN DONKERHOEK 11-12 JUNIE 1900 (I)
}

\author{
deur Kdoor H.F. Nel*
}

The Battle of Donkerhoek (or Diamond Hill as the English used to call it) will have taken place 85 years ago, between 11-12 June of this year. The article below deals with this particular battle.

Tussen 11-12 Junie vanjaar sal dit net mooi vyf en tagtig jaar gelede wees dat die slag by Donkerhoek, of Diamond Hill, soos die Engelse dit noem, plaasgevind het. Hierdie Slag neem om verskeie redes 'n belangrike plek in die annale van die Tweede Vryheidsoorlog in. Miskien dié belangrikste bydrae wat dit gelewer het, was om die wankelende moreel van die Boerekrygers te herstel, hulle vasberade gemaak het om die stryd voort te sit en gevolglik die oorlog met nog byna drie jaar verleng het. Die stryders het dit as 'n nuwe ligbaken van hoop gesien. Tereg het genl. Smuts dan ook opgemerk dat, hoewel die Boere gedwing is om na die Slag terug te trek, dit 'n besielende uitwerking op die krygers gehad het wat kwalik deur 'n werklike oorwinning in krag oortref sou kon gewees het. ${ }^{1}$

Hierdie slag was in die Transvaal, naas die Slag by Dalmanutha, een van die laaste konvensionele slae van die oorlog, wat daarna deur die Boeremagte volgens die guerrilla-beginsels gevoer sou word.

\section{Die inname van Pretoria en daarna}

Om 14 h00 op 5 Junie het veldm Lord Roberts, die Britse opperbevelhebber in Suid-Afrika, Pretoria met 'n mag van meer as 25000 man triomfantlik binnegetrek. Vir hom was dit die hoogtepunt van sy loopbaan en het hy geglo dat die verowering van die hoofstad van die Zuid-Afrikaanse Republiek die bereiking van sy strategiese doelwit meegebring het en dat die einde van die oorlog nou in sig was. ${ }^{2}$

Roberts het hom soos volg hieroor uitgelaat: "he believed the main operations of the army to be over; that both capitals of the allied enemy had been occupied, and that from now on the fighting would be done by many small units operating over large areas of country to repress local troubles, and that he thought the services of the foreign military attachés had been attained and their duties over". ${ }^{3}$
Vir die Britse oorlogskorrespondente was die besettingseremonie van Pretoria, wat 'n hoogtepunt moes gewees het, die klimaks van anti-klimakse. Hulle het verwag dat die Republikeinse mag hier heroïes weerstand sou bied. In stede daarvan het hulle 'n verlate stad gevind, waar Britse troepe bataljon na bataljon in die stofstrate verbymarsjeer het. Vir die oningeligte toeskouer kon dit maklik voorgekom het asof Pretoria maar net besig is om een burgemeester vir ' $n$ ander te verruil. $^{4}$

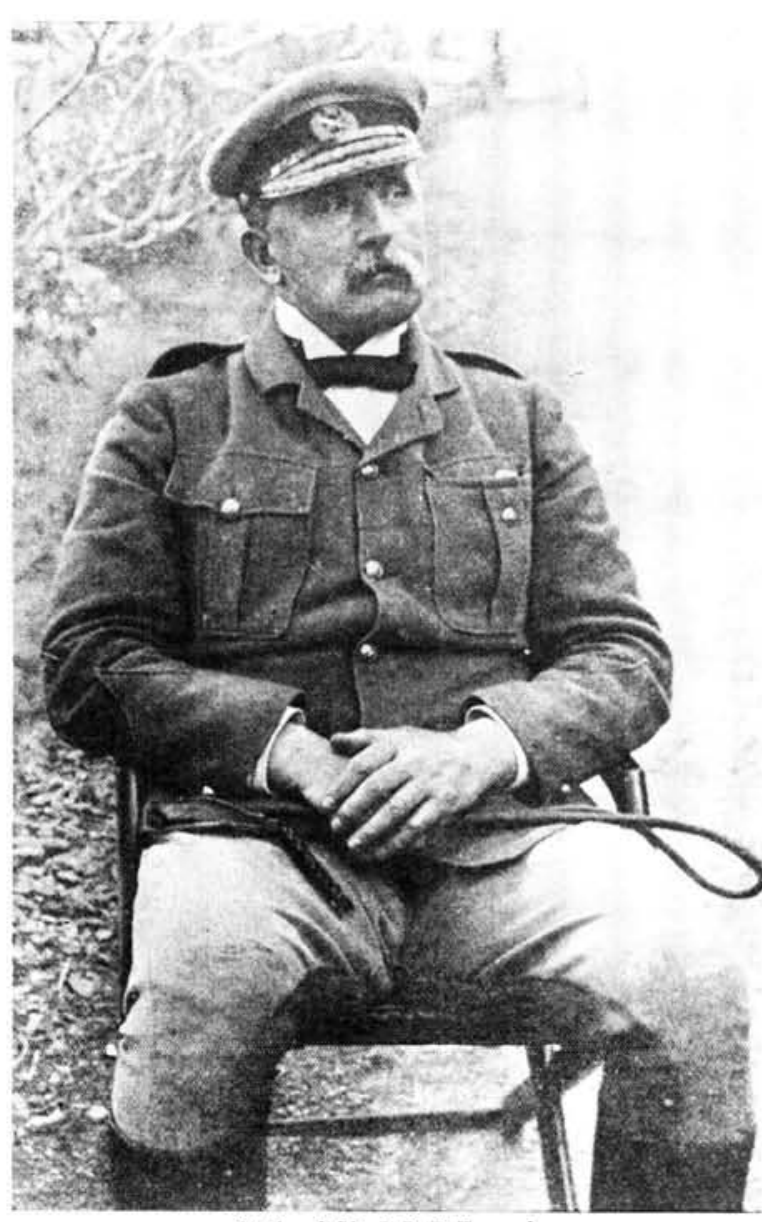

Lt Genl Sir J D P French 
Ook in Engeland is dit in hierdie stadium amptelik in militêre en politieke kringe aanvaar dat die oorlog na die val van Pretoria verby sou wees. Hulle het 'n proklamasie binne enkele dae verwag waarin die inlywing van die Transvaal aangekondig word en dan sou slegs die roetine-take oorbly om die verskillende bendes gewapende Boere uiteen te jaag, ò diegene wat hulself oorgee te ontwapen. ${ }^{5}$

Die onverwagte weerstand wat die Republikeinse magte in die Oranje Vrystaat en by Donkerhoek gebied het, het getoon dat Roberts, en diegene wat sy mening gedeel het, misgetas het. ${ }^{6} \mathrm{Dat}$ dit egter steeds Roberts se vaste oortuiging was dat die einde in sig is, blyk uit sy telegram op 6 Julie aan Lord Lansdowne, die Britse Minister van Verdediging ("Secretary of State for War") waarin hy sê: "I am hoping peace will be made before the end of August."

Roberts se lang gekoesterde sege het egter aan groot gevolge of taktiese onderskeiding mank gegaan, hoewel hy dit nie in daardie stadium besef het nie. Hy het nié daarin geslaag om die vyandelike krysgmiddele ten volle te vernietig of hulle georganiseerde weerstand te onderdruk nie. ${ }^{8}$

Pres. Kruger het gelukkig betyds die nodige maatreëls getref om te verseker dat die Regering vir geval van so 'n gebeurlikheid nie in die vyand se hande beland nie. Op $29 \mathrm{Mei}$, toe inligting oor die Britse vordering noordwaarts daarop gedui het dat die Britse leër Pretoria nog dié nag sou bereik, het die President die Uitvoerende Raad byeengeroep. Daar is toe 'n besluit geneem dat die President, saam met die Staatsekretaris, dr. W.J. Leyds, en ander sleutelamptenare dieselfde nag nog ooswaarts na Machadodorp sou verhuis, wat vanaf 5 Junie as die nuwe regeringsetel geproklameer is. ${ }^{9}$

\section{Moreel van die Boeremagte}

Die val van Pretoria het die moreel van die Boeremagte in die Noorde 'n ernstige knou toegedien. Tereg het genl. Smuts die opmerking gemaak dat aan Boerekant hierdie stad as die heilige der heiliges van die Republiek beskou is en is groot waarde aan die behoud daarvan geheg. In die harte van die burgers het die verwagting gelewe dat Pretoria die groot Armageddon sou wees, waar die gekonsentreerde Boeremagte die beslissende slag sou lewer, wat die Britse leër sou terugwerp na die kus toe, waarvandaan hulle gekom het. Dit was ook hierdie verwagting wat die duisende burgers beweeg het om tydens die rampspoedige terugtog vanaf die Modderrivier, steeds op kommando te bly. ${ }^{10}$

Ook vir genl. Louis Botha, die Waarnemende Kommandant-generaal van die Boeremagte, het die toestand ná die prysgawe van Pretoria maar beroerd gelyk. In 'n breedvoerige verslag aan sy President, op 6 Junie, deel hy mee dat: "onze zaken maar diep beroerd lyken en elke schermutseling en aanraking met den vyand toont meer en meer aan dat onze menschen niet meer willen vechten. Een groote meenigte van onze mannen hebben zicht te Pretoria vrywillig overgegeven. Selfs ook van onze en $\mathrm{u} \mathrm{H}$ Ed boezem vrienden en steunpilaren hebben zich ook tot myne verwondering en teleurstelling overgegeven, mannen die hun heel bestaan aan de Republiek te danken hebben ...."11

Op 7 Junie het Botha bostaande rapport aangevul met mededelings dat 'n groot gedeelte van die burgers, waaronder alle Rustenburgers en die grootste gedeelte van die Westergrens-burgers, huistoe gegaan het en dat geen invloed hulle aan die front kon hou nie. Die meeste van genl. De la Rey se mense was ook weg en die Soutpansbergers het hul na slegs drie dae aan Botha se front eenparig uit die voete gemaak. Ook Smuts verwys na die totale insinking in die Boerkrygers se gevegsdrif in hierdie tyd: "If Pretoria had seen the higher Boer officers at their lowest ebb of determination the week that intervened between its fall and the battle of Donkerhoek ... saw the lowwater mark of the morale of the Boer rank and file." 12

So groot was die omvang van die hensoppery dat die Britse Militêre Goewerneur van Pretoria op 14 Junie in 'n amptelike bulletin bekend gemaak het dat tussen 4000 en 5000 gewere sedert die verowering van die stad daar neergelê is. ${ }^{13}$

Roberts het intussen 'n besoek van Botha se sekretaris ontvang, wat met die boodskap gekom het dat die Waarnemende Kommandant-generaal vredesonderhandelinge wou voer. Hierdie aas het Roberts, soos Botha verwag het, met hoek en al ingesluk en hom die kans gegee om uit die kake van die vyand te ontsnap..$^{14}$

\section{Terugtog van die Boeremagte}

Botha het nou geen ander keuse gehad as om voor die Britse oormag terug te wyk en sy krygsmag ter beskering van die Regering, maar 
veral van die Republiek se enigste verbindingslyne met die buitewêreld, waarlangs buitelandse voorrade ingevoer kon word, in die stellings voor Donkerhoek voor die vyand te werp nie. ${ }^{15}$

Anders as wat die Engelse verwag het, het die verowering van die Transvaalse hoofstad nie die Boereweerstand beëindig nie; inteendeel, nadat Louis Botha vir Roberts laat weet het dat hy die Stad nie meer sou verdedig nie in die vroeë môre ure van 5 Junie in die saal gespring en na 'n kort, kragtige: "Kom kêrels! Ons sal hulle tot die dood toe beveg!" sy Kommando uit Pretoria uitgelei. ${ }^{16}$

Van Pretoria af het Botha sy burgers ooswaarts na Pienaarspoort, waar die Delagoabaaispoorlyn deur die Magaliesberge gaan, gelei. By Eerstefabrieke, wat hy as versamelpunt van die kommando aangewys het, het hy 'n Krygsraad byeengeroep in die kantoor van die whiskeydistileerdery van Lewis en Marks, op die plaas Hatherley, wes van Pienaarspoort. ${ }^{17}$

Op geen stadium sedert die uitbreek van die oorlog was die Transvaalse krygsleiers deur so 'n gees van pessimisme en moedeloosheid oorval soos toé die geval was nie. Om 11 h00 het Louis Botha die kantoor, waar die ander offisiere reeds gewag het, binnegekom. 'n Donker skaduwee het oor sy gesig gehang en in die plek van die kenmerkende helder blik in sy groot blou oë, was 'n uitdrukking van diepe neerslagtigheid. Hy het 'n kort oorsig van die situasie gegee. Die toestand, het hy hulle voorgehou, was ernstig, maar nie hopeloos nie. Daarna het genls De la Rey en Lemmer die woord gevoer. Hulle het 'n somber prentjie vir die Krygsraad geskets. Die burgers se moreel was verpletter; hulle het geweier om verder te veg en het in groot getalle huiswaarts gekeer; hulle klere was in vodde en die perde in ' $n$ jammerlike toestand, want die veld was droog en die weiding swak, die offisiere het nie meer kontantgeld vir die aankoop van voer en proviand gehad nie en niemand was meer bereid om voer teen kommandeerbriewe aan die kommando's te lewer nie. Die Kommandant-generaal, sou nie meer verder op die dienste van hul kommando's kon staat maak nie. De la Rey het ook gedreig om met sy getroue burgers van Lichtenburg, Rustenburg en Marico na sy tuisdistrik te gaan, 'n Republiek van Wes-Transvaal uit te roep en dan tot die laaste man teen Engeland te veg. ${ }^{18}$

Uiteindelik het die Krygsraad besluit om "Voorlopig de bergketen Wonderboomspoort tot Donkerhoek en vandaar zuid naar de omstandighede in bezit te nemen en te verdedigen en dan zoo spoedige mogenlijk weer een krygsvergadering van alle officieren byeen te roepen om verder wyze van handeling te bespreken." 19

Na afloop van die Krygsraad het die offisiere onverwyld begin om, in ooreenstemming met bogemelde besluit, stelling in te neem en teen skemer dié aand het Smuts aan pres. Kruger getelegrafeer dat die kommando's voorlopig posisies inneem van Wonderboompoort tot Suikerbosrand, 'n verdedigingskema waaraan die President sy heelhartige goedkeuring geheg het. ${ }^{20}$

\section{Ontplooiing van Botha se magte}

Onderwyl De la Rey noord van Pretoria geopereer het, het die res van die Boerekommando's gedurende die 6de voortgegaan om posisies in te neem in die Magaliesbergreeks vanaf Derdepoort suidwaarts oor Donkerhoek.

Die linie waarlangs die Boere stelling ingeneem het, was geleë in 'n vesting van heuwelkettings en ruwe terrein, wat 'n wye gebied ten ooste van Pretoria, vanaf Krokodilspruit in die noorde tot verby die oorsprong van die Pienaarsrivier in die suide geloop het. ${ }^{21}$ Noord van Pretoria vorm die Magaliesberge 'n natuurlike skans, wat van wes na oos na Franspoort strek. Oos van hoofstad is daar twee parallelle kettings, wat $11 \mathrm{~km}$ uitmekaar suidooswaarts lê, tw die Magaliesbergreeks, wat vanaf Franspoort in laasgenoemde rigting voortgesit word, en die Bronberge ten weste daarvan. Alle weë na die landstreek oos daarvan het deur verskeie poorte in hierdie bergkettings gelei en is volkome deur die omliggende terrein oorheers. ${ }^{22}$

Sewe-en-twintig kilometer oos van Pretoria het die spoorlyn na Delagoebaai deur Pienaarspoort, 'n diep ravyn in die Magaliesbergreeks, geloop. Ses kilometer oos daarvan was Vandermerwestasie, wat teen 7 Junie die westelike eindstasie vir treinverkeer vanaf Komatipoort was. ${ }^{23}$

Aan weerskante van Pienaarspoort is twee hoë, lang heuwelkoppe, elk sowat 5,5 km lank, wat onderskeidelik noordwaarts tot by Franspoort en suidwaarts tot by Donkerhoek strek. Hierdie gedeelte het die sentrum van Botha se linie uitgemaak en was van nature so uitmuntend geskik vir verdediging dat dit uit die aanvaller se oogpunt as 'n feitlik onneembare posisie beskou is. Dit het aan Botha die voordeel gebied dat hy dit met 'n relatiewe swak mag kon verdedig en soveel van sy 
beskikbare burgers soos moontlik op sy flanke kon plaas. ${ }^{24}$

Van Franspoort af noordwaarts het Botha sy regterflank meer as 16 kilometer ver oor 'n reeks gebroke rante ontplooi en die verste punt daarvan uiteindelik op die hoogtes rondom Krokodilspruit geanker. Suidwes van Krokodilspruit strek Kameelfonteinvallei ongeveer $7 \mathrm{~km}$ ver uit tot by Kameelspuit. Die vallei is sowat $3 \mathrm{~km}$ breed en word aan die noordekant begrens deur die Boekenhoutskloofrante en aan die suidekant deur die Kameelfonteinrant. Die westelike punt van lg rant styg skerp en vorm 'n hoë koppie, bekend as Louwbaken, wat die res van Kameelfonteinrant en die hele vallei domineer. 'n Diep kom skei Louwbaken van die noordelike punt van Kameelfonteinrant, bekend as Krokodilspruitkop $3 \mathrm{~km}$ daarvandaan. Oos van Krokodilspruitkop skei 'n $2 \mathrm{~km}$ breë kloof, waarlangs Krokodilspruit vloei, Kameelfonteinrant van die hoë terrein bokant Tweefontein. ${ }^{25}$

Botha se linkerflank het vanaf Donkerpoort suidwaarts gelê. Die Magaliesberge strek van daar af in 'n gebroke reeks suidooswaarts oor Diamond Hill en Morskop totdat dit uiteindelik oos draai en ongeveer $8 \mathrm{~km}$ suid van Bronkhorstspruitdorp verbygaan. By Mooiplaats, Kleinfontein en Tweedracht vorm groot bosagtige uitlopers 'n heuwelketting teenaan die oostelike oewer van die Pienaarsrivier, wat ewe sterk posisies as die hoofstellings bied. Suid van Morskop draai die hoë terrein na die weste en suidweste oor Rooikoppies en Kameelkraal verby die oorspronge van die Pienaarsrivier en sluit uiteindelik suid van Tierpoort by die Bronbergreeks aan. ${ }^{26}$

In hierdie moeilike, bergagtige terrein het Louis Botha sy burgers langs ' $\mathrm{n}$ linie van meer as $40 \mathrm{~km}$ oftewel 6 uur te perd, laat stelling neem. Vanuit dié posisies het hulle die Delagoabaai-spoorlyn, en min of meer alle ander weë van betekenis wat na Oos-Transvaal gelei het, afgesny. Kennende vir Roberts het Botha geweet dat dié sy flanke, met veral sterk ruitery sou bedreig, sodat hy soveel versterkings as moontlik van sy middelpunt daarheen moet stuur. Die Engelse magte sou daarna ' $n$ deurbraak by Pienaarspoort in die middel probeer uitvoer. Die Kommandant-generaal het gevolglik sy flanke so sterk as moontlik gemaak om Roberts se ruitery-aanslag beter te kon weerstaan. Die natuurlike sterkte van die middel het hom in staat gestel om dit met 'n relatief swakker mag te beskerm. ${ }^{27}$

Op 7 Junie is daar weer 'n Krygsraad in die omge- wing van Vandermerwestasie gehou. Die berig van De Wet se suksesse teen die Britse magte in die Vrystaat het vir 'n groter gees van optimisme onder die aanwesiges gesorg. ${ }^{28}$

Die Krygsraad het dan ook eenparig besluit om: "lettende op die wenschelijkheid zoo spoedig mogenlijk alle commandos te reorganiseeren ... de Rand bergen Pienaarspoort en Donkerhoek randen thans in bezet van onze commandos te houden ten einde de officieren in de gelegenheid te stellen hunne manschappen zoo spoedig mogenlijk by een te brengen." ${ }^{29}$ Tweedens is besluit om "De Regeling van de commandos over te laten aan den Commandant generaal volgens Krygsraadbesluit genomen te Pretoria." ${ }^{30}$ Dit het daarop neergekom dat die krygsrade afgeskaf, en die besluitneming aan die Kommandant-generaal oorgelaat sou word.

Die Kommandant-generaal was nou vasbeslote om in sy linie vas te skop en Roberts se oormag, voor wie die Boere van Belmont af aanhoudend moes terugwyk, hard terug te slaan. Daardeur sou hy die burgers se moreel en hulle geloof in hul vermoë om die Britse leër suksesvol teen te staan, herstel. Na die Krygsraad se besluit om die stellings wat hulle ingeneem het te behou en die ontplooiing van die Kommando's aan die waarnemende Kommandant-generaal oor te laat, het Botha met onvermoeide ywer sy aandag aan veelvuldige sake gewy ten einde sy krygsmag vir die verwagte geveg voor te berei. ${ }^{31}$

Die bevelvoerders van die Britse magte het nou voortdurend die Boerelinies deur hulle berede elemente laat verken en probeer om die ankerpunte van Botha se skynbaar nimmereindigende flanke te bepaal. Broadwood het teruggerapporteer dat die omvleueling van die Donkerhoekposisies nou 'n baie moeilike onderneming geword het, aangesien die Britse verkenningsaktiwiteite hul voorgenome omvleuelingsbeweging vir die vyand blootgelê het, as gevolg waarvan die Boere hulle linkerflank verder uitgestrek en versterk het. Hy het ook gevind dat die Boere geweldig aktief en aggressief was. ${ }^{32}$

Op die regterflank van Botha se linie, dws van Franspoort af noordwaarts, was De la Rey in bevel. By Franspoort was veggenl C.M. Douthwaite van die Potchefstroom-kommando en net noord van hom asst genl F.A. Grobler met 200 Waterbergers. Verder noord het assts genl S.P. du Toit met die Wolmaranstad- en Bloemhofkommando's posisie ingeneem, gevolg deur die Griekwalanders onder veggenl P.J. Liebenberg en 
die Lichtenburg-kommando onder kmdt H.C.W. Vermaas. Op die uiterste regterflank het asst genl J.P. Snyman met die Marico-burgers die linie geanker. Die geledere van die burgers was egter so uitgedun dat De la Rey se totale mag kwalik 2000 man getel het. Met uitsondering van die burgers by Franspoort, het hy die res van sy mag hoofsaaklik op die Kameelfonteinhoogtes geplaas, met kleiner afdelings in die gapings tussenin. Dertien kanonne onder kapt Alfred von Dalwig het op hierdie flank aan De la Rey vuursteun verskaf. ${ }^{33}$

Die middelpunt en suidelike flank, dws die hele linie suid van Franspoort, is deur Botha self aangevoer. Sy kommando's was soos volg opgestel. Tussen Franspoort en Pienaarspoort het veggenl Oosthuizen met 250 Krugersdorpers stelling geneem. Pienaarspoort is gehou deur veggenl H.R. Lemmer, met onder andere die Middelburg- en Lydenburg-kommando's en die Polisie van kmdt G.M.J. van Dam. Onder sy bevel was ook kmdt Blignaut en vk Theunissen. Teen 11 Junie was sy mag sowat 350 man sterk.

Die rant tussen Pienaarspoort en Donkerhoek is deur die Germiston-kommando onder kmdt G.H. Gravett beset. Die artillerie in die middel het bestaan uit die Long Tom op die spoorwegwa by Vandermerwestasie en 3 veldkanonne. ${ }^{34}$

Die suidelike flank is soos volg ontplooi: by Donkerpoort, waar die wapad deur die poort gegaan het, was kmdt Ben Viljoen met 150 Johannesburgers. Op die Donkerhoekplato was 'n veldkornetskap Krugersdorpers, 45 man sterk, onder kmdt J.C.G. Kemp, terwyl Diamond Hill aan Tobias Smuts met sowat 500 burgers van Ermelo toevertrou is. Suidwaarts na Morskop het vk Koen Brits met 'n veldkornetskap Standertonners gelê, gevolg deur die Middelburg en Bethalkommando's, laasgenoemde onder vk Grobler. Die gebied Morskop-, Tierpoort en die posisies by Tierpoort self is beset deur kmdt Buys met die Heidelbergers, vk Dercksen met die Boksburgers en 'n klein Duitse Korps onder kmdt Kuntze. Hierdie kommando's het onder veggenl J.C. Fourie gestaan en was gesamentlik sowat 300 man sterk. ${ }^{35}$

Die artillerie op die Boere se linkerflank het bestaan uit: drie $75 \mathrm{~mm}$ Creusot-kanonne en 'n 37 Pom-pom op 'n koppie, vanwaar die vyand in sy regterflank bestook kon word; drie C96 Krupps $(75 \mathrm{~mm})$ en ' 12 ponder-Armstrong by Tierpoort, en twee Pom-poms in die middel van die suidelike flank, dws in die Kleinfontein - Dia- mond Hill - omgewing, 'n totaal dus van 7 veldkanonne en 3 Pom-poms. ${ }^{36}$

Met 'n mag van ongeveer drie-en-'n-half tot vierduisend burgers en meer as twintig kanonne het genl Botha die Britse aanval afgewag. Die Britse leërleiding het voor die slag by Donkerhoek die sterkte van die Boeremagte op hierdie front op byna dubbel so hoog, tw op 7000 man geskat. ${ }^{37}$

\section{Die Britse Magte}

Siekte, gevegsverliese en die agterlating van garnisoenmagte en beskermingselemente langs sy verbindingslinies het Roberts se leër so uitgedun dat hy uit die meer as 39300 man, wat sedert sy opmars uit Bloemfontein in die begin van Mei na Pretoria opgeruk het, slegs ongeveer 20000 man met 74 kanonne vir die aanval op Botha se linie kon monster. Die berede magte was die swaarste getref en, vanweë die verlies aan perde, so uitgedun dat brigades feitlik gekrimp het tot die sterkte van regimente, en regimente tot dié van eskadrons. French se ses ruitery-regimente, wie se vasgestelde oorlogsterkte 3186 moes wees, het saam slegs sowat 800 man getel, terwyl sy artilleriebatterye, weens gebrek aan perde, tot vier kanonne elk gekrimp het. ${ }^{38}$

\section{Roberts se krygsplan}

Om die oorlog te beëindig moes Roberts die Transvaalse hoofmag militêr vernietig. Weens sy verswakte mag en die bedreiging van die Vrystaters in sy rug het hy nie kans gesien om onmiddellik die offensief te hervat nie. Die herstellende Boeremagte so naby Pretoria het ook vir hom groot gevaar ingehou en dit het hom nie toegelaat om op versterkings te wag nie. Hy het nou besef dat Louis Botha gladnie voornemens was om oor te gee nie, maar besig was om sy strydkragte te reorganiseer en om hulle gevegsdrif te probeer herstel. Hy wou hulle dus verdryf tot waar hulle nie meer vir hom 'n direkte bedreiging sou wees nie. ${ }^{39}$

Roberts het besef dat 'n frontaanval, vanweë die Boeremagstellings se natuurlike sterkte, vir hom swaar verliese sou meebring. Hy het dus sy aanvalsplan met die oog daarop geformuleer om die Boerelinie met sy berede magte in 'n wye knyptangbeweging op albei flanke te omvleuel en hulle terugtoglinie af te sny. Terselfdertyd sou hy hulle in die rug probeer aantas. Uit ervaring het hy geweet dat die Boere terugtrek sodra hulle in die rug bedreig word. Presies oor hoe ver die 
Boereflanke, wat omvleuel moes word, noord- en suidwaarts gestrek het, het Roberts en sy staf in onkunde en onsekerheid verkeer - onkunde wat hom duur te staan sou kom. Volgens die Britse stafdagboeke was hulle inligting op 10 Junie, die dag waarop Roberts sy orders vir die aanval gegee het, dat: "The Boer position extended from Leeuwfontein along the high and steep ridge from Franszpoort by Rhinocerospoort to above Donkerhoek. ${ }^{40}$

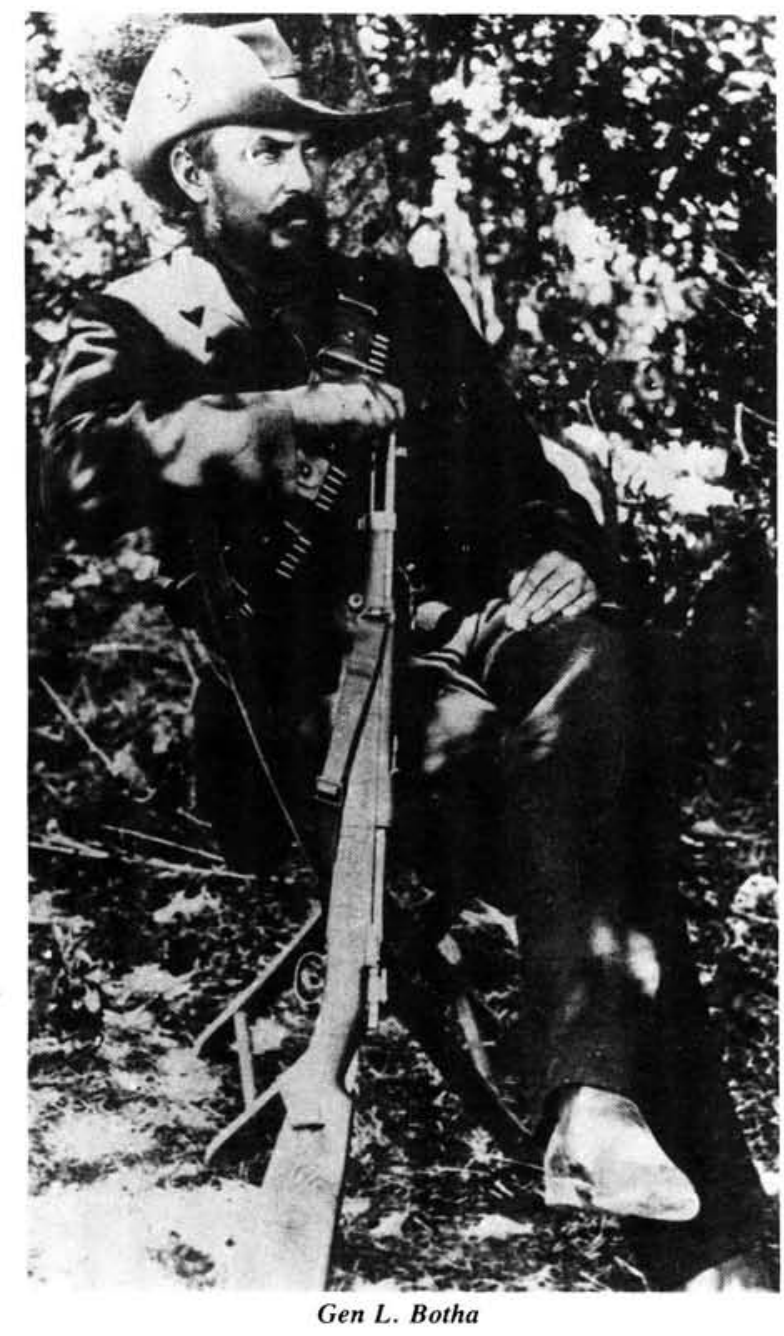

Op Sondag 10 Junie, het Roberts vir genls French, Pole-Carew, Ian Hamilton, Broadwood en Gordon na Pretoria ontbied en sy bevele vir die aanval uitgereik. French se opdrag was om met 1 en 4 ruitery-brigades links om te beweeg en die Boerelinie aan die noordekant in die Kameelfonteingebied te omvleuel. Daarna moes hy suidwaarts swenk en die spoorlyn in die omgewing van Elandsrivier in die vyand se rug afsny. Terselfdertyd moes Ian Hamilton met 2 en 3 ruiterybrigades en Ridley se berede infanterie, ondersteun deur 21 infateriebrigade, die vyandelike stellings aan die suidekant omvleuel. Pole-Carew moes met 11 divisie en sy vesting- en vlootka- nonne vanaf Christenen Hall teen die Boeresentrum demonstreer, terwyl Henry se berede infanterie die gaping in die rante by Franspoort moes dek. ${ }^{41}$

Die sterktes van Pole-Carew en Ian Hamilton se magte word onderskeidelik deur Britse bronne op hoogstens 6000 man, met 20 kanonne, en 6400 man gestel. Dié gegewens is skynbaar nie betroubaar nie. Pole-Carew se artillerie alleen het 33 persent meer getel as wat Churchill beweer het en in die lig van Roberts se eie getuienis oor die sterkte van sy hele mag en dié van French, moes die Britse magte, in die middel en suide gesamentlik, in die omgewing van 18000 man getel het. Met 'n oormag dus van meer as vyf man teen een en van drie tot vier kanonne teen een sou Roberts die goed voorbereide Boerelinie aandurf. ${ }^{42}$

In die volgende uitgawe van Militaria sal die verloop van die Slag by Donkerhoek op 11 en 12 Junie 1900 beskryf word.

\section{*H.F. Nel (Kdoor - aftr) MA, B Educ. HOD.}

\section{Bibliografie}

1. Battersby, HF.P., In the Web of a War (1900), pp $220-7$.

2. A.E. Breytenbach, "Die Slag by Donkerhoek $11-12$ Junie 1900", Ongepubliseerde MA verhandeling, Universiteit van Pretoria, 1979, p 1; Pakenham, Thomas: The Boer War, p 433 .

3. Reports on Military Operations in South Africa and China. Verslag van kapt S.B.H. Slocum, Amerikaanse militêre attache by die Britse Magte, p 77.

4. Pakenham, Thomas: The Boer War, p 433.

5. Soos aangehaal uit A.E. Breytenbach, "Die Slag by Donkerhoek $11-12$ Junie $1900^{\circ}, \mathrm{p} 2$.

6. Ibid, 33 .

7. Confidential Telegrams, p 183, № 284A, Roberts aan SSW 6 Jul 1900.

8. Soos angehaal in A.E. Breytenbach, "Die Slag by Donkerhoek $11-12$ Junie 1900". p 32

9. W.K. Hancock en J. van der Poel, Selections from the Smuts Papers $I$, p 538.

10. Ibid, pp 537 en 543

11. Soos aangehaal uit A.E. Breytenbach, "Die Slag by Donkerhoek $11-12$ Junie $1900^{\circ}$. pp $12-13$.

12. Ibid, pp $12-13$.

13. Ibid, p 14 .

14. Pakenham, Thomas, The Boer War, p 433.

15. A.E. Breytenbach, "Die Slag by Donkerhoek 11 - 12 Junie 1900", p 41

16. Soos aangehaal uit A.E. Breytenbach, "Die Slag by Donkerhoek II - 12 Junie $1900^{\circ}, \mathrm{p} 44$.

17. Leyds 770, P.A. Nierstrasz, Der Süd Afrikanische Krieg II. (Band 5) pp 937 - 938; The Times History of the War in South Africa, iv, pp 273-274.

18. A.E. Breytenbach, "Die Slag by Donkerhoek $11-12$ Junie 1900", p 47

19. Leyds 744; pp 16 - 17, Notulen van Krygsraad gehouden te Eerste Farbieken op Dinsdag, 5 Junie 1900

20. Soos aangehaal uit A.E. Breytenbach, "Die Slag by Donkerhoek $11-12$ Junie $1900^{\circ}, \mathrm{p} 50$.

21. Vergelyk die topografiese kaart vir die terreinbesKrywing.

22. A.E. Breytenbach, "Die Slag by Donkerhoek 11 - I2 Junie 1900", p 58

23. Ibid, $\mathrm{p} 58$.

24. Ibid, p 58.

25. Ibid, $\mathrm{p} 59$

26. Ibid, 59

26. Ibid. $\mathrm{p} 60$.

28. 0 von Lossberg, Mit Santa Barbara in Süd Afrika, pp 120 - 124

29. Leyds 739, p 114, Telegr van Botha aan Kruger, 7 Junie 1900.

30. Ibid

31. A.E. Breytenbach, "Die Slag by Donkerhoek 11 - 12 Junie 1900" pp 57 61 